\title{
ON APPROXIMATION PROPERTIES OF GENERALIZED $q$-BERNSTEIN-KANTOROVICH OPERATORS
}

\author{
LAKSHMI NARAYAN Mishra AND DHAWAL J. BHATT
}

\begin{abstract}
In this paper, we develop a generalization of $q$-Bernstein-Kantorovich type operators. We first study some fundamental properties of these operators and then investigate approximation properties of a sequence of these operators using Korovkin theorem. Finally, we estimate rate of approximation by modulus of continuity.
\end{abstract}

Mathematics subject classification (2010): 41A10, 41A25, 41A36.

Keywords and phrases: Korovkin theorem, Bernstein operator, $q$-integers, modulus of continuity.

\section{REFERENCES}

[1] S. N. Bernstein, Demonstration du Theorem de Weierstrass Fondee sur le Calculu des Probabilites, Comm. Soc. Mat. Charkow Ser., 13(1912), 1-2.

[2] H. Bohman, On Approximation of Continuous and Analytic Functions, Ark. Math., 2(1952), 43-57.

[3] J. D. CAO, A generalization of the Bernstein Polynomials, J. Math. Anal. and Appl., 209(1997), 140146.

[4] O. Dalmanoglu, Approximation by Kantorovich type q-Bernstein operators, in Proceedings of the 12th WSEAS International Conference on Applied Mathematics, Cairo, Egypt, (2007), 113-117.

[5] A. R. Gairola, Deepmala and L. N. Mishra, Rate of approximation by finite iterates of $q$ Durrmeyer operators, Proc. Natl. Acad. Sci. India Sect. A, 86, 2(2016), 229-234.

[6] H. Gauchman, Integral Inequalities in Calculus, Comput. Math. Appl., 47, 2-3(2004), 281-300.

[7] A. Ilinskit And S. Ostrovska, Convergence of generalized Bernstein polynomials, J. Approx. Theory, 116(2002), 100-112.

[8] A. IZgI, Approximation by a Class of New Type Bernstein Polynomials of one and two variables, Global Journal of Pure and Applied Mathematics, 9, 1(2013), 55-71.

[9] F. H. JACKSON, On the q-definite integrals, Quart. J. Pure Appl. Math., 41(1910), 193-203.

[10] L. V. Kantorovich, Sur certains developments suivant les polynomes de la forms de S. Bernstein I, II, C. R. Acad. Sci. USSR, 20(1930), 563-568.

[11] P. P. Korov KIn, On Convergence of Linear Positive Operators in the Space of Continuous Functions, Dokl. Akad. Nauk SSSR, 90(1953), 961-964.

[12] G. G. LoRENTZ, Bernstein polynomials, Chelsea, New York, 1986.

[13] A. LuPAS, A q-analogue of the Bernstein operator, Seminar on Numerical and Statistical Calculus, University of Cluj-Napoca, 9(1987), 85-92.

[14] V. N. Mishra, K. Khatri, L. N. Mishra, Statistical approximation by Kantorovich type Discrete q-Beta operators, Adv Differ Equ 2013, 345 (2013), doi:10.1186/1687-1847-2013-345.

[15] H. ORUC AND N. TunCER, On the Convergence and Iterates of $q$-Bernstein Polynomials, J. Approx. Theory, 117, 2(2002), 301-313.

[16] S. Ostrovska, On the Lupas q-analogue of the Bernstein Operator, Rocky Mountain. J. Math., 36, 5(2006), 1615-1629.

[17] S. Ostrovs KA, q-Bernstein Polynomials and Their Iterates, J. Approx. Theory, 123, 2(2003), 232 255.

[18] G. M. PhILIPS, Bernstein Polynomials Based on the q-integers, Ann. Numer. Math., 4(1997), 511518. 
[19] G. M. Philips, A Generalization of the Bernstein Polynomials Based on the q-integers, Anziam J.,42(2000), 79-86.

[20] M. A. Siddiqui, R. R. Agrawal And N. Gupta, On a class of modified new Bernstein operators, Adv. Stud. Contemp. Math. (Kyungshang), 24, 1(2014), 97-107.

[21] K. K. Singh, A. R. GAiRola AND DeEPMALA, Approximation theorems for q-analouge of a linear positive operator by A. Lupas, Int. J. Anal. Appl., 12, 1(2016), 30-37.

[22] V. N. Mishra, K. Khatri, L. N. Mishra, Deepmala, Inverse result in simultaneous approximation by Baskakov-Durrmeyer-Stancu operators, Journal of Inequalities and Applications 2013, 2013:586. doi:10.1186/1029-242X-2013-586. 